\title{
Editorial V.12 N.25
}

\section{Daniela Novelli}

Doctor, Univ ersidade do Estado de Santa Catarina / danovelli@gmail.com Orcid: 0000-0001-6981-8933/ lattes

\section{Alberto da Silva}

Doctor, Univ ersité Paris-Sorbonne / a.dasilva8888@gmail.com

Orcid: 0000-0000-0000-0000

\section{Sandra Regina Rech}

Doutora, Universidade do Estado de Santa Catarina / sandra.rech@udesc.br Orcid: 0000-0002-0062-691 4 / lattes 
This dossier presents the theme Ibero-Latin American Fashion and Cinema, proposing a reflection on various historical, sociocultural, political and/or economic contexts linked to the Ibero-Latin American visual culture from two charming and instigating universes: Fashion and the Cinema.

From our gratifying and inspiring meetings in Paris and Florianopolis, the desire to (re) think above all Latin and Iberian America as a space perceived relatively homogeneous by Europe and the United States throughout the twentieth century, even in our days. In this direction, we select works that analyze and question both forms of exhibition of (un) pretentious identities to recognition, as well as collective and visual representations that incorporate in the contemporary subjects, divisions of the social world organized through the corporeal and symbolic appearance, generally from perceptions schemas based on certain racial, ethnic, generational, class, gender and/or sexual power relations.

Specifically, the article Cinema as trendsetter and source of historical research in fashion proposes a classification of cinema costumes, analyzing films of the musical genre produced in the 1960s and 1970s, based on a line of research centered on the influence exerted by the cinema about the construction of young culture trends.

For its part, the text Dressing's ruptures: an analysis of Vestido Nuevo and the formation of gender identity in childhood brings to light social practices that express, dialogue and/or challenge discourses through the canvases and the dressing choices of the main character. The dialogue 
between fashion and cinema is fertile to deal with gender issues in the school context, raised in the 2007 Spanish short film Vestido Nuevo.

In the sequence, the article The photographs of Tônia Carrero and its construction as national star through the images conveyed in The Cruise and Scena Muda (19471955) establishes important relations between the construction of the image of Tônia Carrero as star of the national cinema by means of her photographs at a historical moment marked by the industrialization of Brazilian cinematographic production. In this sense, it was essential to wear clothes, accessories, and poses that connected the actress's image to the glamor or naive eroticism of pin-ups, elements that were equally explored by Hollywood cinema.

Following the line of reflections on the dissemination of media images and cultural stereotypes in the Latin American context, the article The inflamed Argentina of Vogue Paris presents a consistent analysis on the fashion editorial Tango des Passions, published in a French edition of the periodical Vogue consecrated to Argentina, in February 2006. A symbolic approximation of the cultural transmission links between Europe and Argentina is highlighted, from a discursive construction based on philia, one of the fundamental attitudes that govern the representation of the Other in intercultural dialogue.

Finally, the article Boi Neon: fashion as a metaphor of the contemporary and experience of the sensitive aims to understand the identity dimensions of the contemporary subject, through the character Iremar of the Brazilian feature film Boi Neon, released in 2015. From a judicious scene analysis guided by a film methodology analysis of images, it was possible to verify that the narrative of the work under analysis leads to the contemporary world of sensations and breaks stereotypes and paradigms. 
Therefore, the selected articles reveal, in general, how hierarchical and unequal cultural models of identification come on the scene to (de)construct imagery and challenge mentalities in the light of new looks, places, and other perspectives. Result of a work of competent editorial consultants, dossier coordinators, evaluators, technical staff and researchers.

We invite each reader to go through the pages of this dossier with eyes and minds attentive to the rich dialogue between fashion and cinema, universes here thought from the Ibero-Latin American context, which can be disseminated without moderation, with votes for a great reading! 